\title{
Análise do conteúdo tecnológico das exportações brasileiras sob a lógica estruturalista-kaldoriana
}

Analysis of the technological content of Brazilian exports under the structuralistKaldorian logic

\begin{abstract}
This study analyzed the technological content of Brazilian exports to verify if the expansion of exports between 2000 and 2005 would be able to induce sustained economic growth following the structuralist-Kaldorian logic. For this, we used the input-output matrices provided by the IBGE and made compatible based on the taxonomy proposed by Lall (2000). The findings show that despite the recorded improvement in the country's commercial result in the analyzed period, the increase in Brazilian exports would not be able to induce a virtuous circle of sustained economic growth. Under the structuralistKaldorian hypothesis, this may be credited to the concentration of export expansion in low technological content sectors that, in the long run, would not cause the rupture of the external constraint to economic growth in the country. This suggests that the Brazil's National Innovation System still has a low level of development with limited role in inducing economic activity.
\end{abstract}

\section{Keywords}

technological content of exports; sustained growth; input-output; hypothetical extraction method.

JEL Codes C67; F43; O33.

\author{
Joilson de Assis Cabral \\ Universidade Federal Rural do Rio de Janeiro \\ Maria Viviana de Freitas Cabral \\ Universidade Federal Rural do Rio de Janeiro \\ Daniel Ribeiro de Oliveira \\ Universidade Federal Rural do Rio de Janeiro
}

\section{Resumo}

Este estudo analisou o conteúdo tecnológico das exportações brasileiras para verificar se a expansão das exportações ocorrida entre $2000 e$ 2005 seria capaz de induzir o crescimento econômico sustentado seguindo a lógica estruturalista-kaldoriana. Para tanto, foram utilizadas as matrizes de insumo-produto disponibilizadas pelo IBGE, compatibilizadas com base na taxonomia proposta por Lall (2000). Os resultados do estudo mostram que, apesar da melhora do resultado comercial do país verificada no período analisado, o aumento das exportações brasileiras não seria capaz de induzir um círculo virtuoso de crescimento econômico sustentado. Sob a lógica estruturalista-kaldoriana, esse fato pode ser creditado à concentração da expansão das exportações nos setores de baixo conteúdo tecnológico que, no longo prazo, não causaria a ruptura da restrição externa ao crescimento econômico do país. Essa constatação sugere que o Sistema Nacional de Inovação brasileiro ainda apresenta um baixo grau de desenvolvimento com papel limitado na indução da atividade econômica.

\section{Palavras-chave}

conteúdo tecnológico das exportações; análise kaldoriana; insumo-produto; método de extração hipotético.

Códigos JEL C67; F43; O33. 


\section{Introdução}

A articulação entre o Estado, o capital nacional e o capital estrangeiro, surgida no modelo de substituição de importações, resultou na política industrial que proporcionou uma modernização da estrutura produtiva brasileira no final da década de 1970 (Kupfer, 2005). Entretanto, o modelo de substituição de importações privilegiou a importação de tecnologia ao invés de estimular o desenvolvimento de uma tecnologia local (Lamonica et al., 2012). Segundo Fajnzylber (1983), quando se cria uma indústria desprovida de um "núcleo endógeno de dinamização tecnológica"1 não se poderia superar a vulnerabilidade externa pertinente às economias periféricas.

Diante da ausência de endogeneização do processo técnico da indústria brasileira, o modelo de substituição de importações não conseguiu construir uma base institucional capaz de impulsionar o progresso técnico, ou seja, o modelo de industrialização brasileira foi incapaz de articular um sistema nacional de inovação (SNI) eficiente e maduro. Nessa percepção, Lamonica et al. (2012) afirmam que a inexistência ou insuficiência de uma estrutura científica e tecnológica interligada ao sistema produtivo gera assimetrias tecnológicas. Sendo assim, um SNI incompleto aliado à estagnação econômica da década de 1980 fez com que a estrutura produtiva brasileira iniciasse a década de 1990 defasada tecnologicamente. Somente após a abertura comercial e a conquista da estabilidade econômica da década de 1990, foram criadas condições desejáveis para uma nova fase de modernização da indústria brasileira. De acordo com Ferraz et al.(1995), a partir desse momento intensificaram-se e generalizaram-se novas técnicas de organização da produção, além de profundas reestruturações no processo produtivo, o que propiciou ganhos significativos de produtividade em curto período de tempo, sem exigir a realização de grandes investimentos.

Dada esta nova perspectiva de modernização industrial, crescimento econômico interno e crescimento econômico mundial, a economia brasileira passou por um período de expansão econômica nos primeiros anos da década de 2000. Como resultado desse cenário favorável, ocorreu uma reversão nos fluxos de comércio exterior do país: em 2000, a balança comercial brasileira apresentou um déficit de US $\$ 697,7$ milhões, tornando-

1 Fajnzylber (1983) define "núcleo endógeno de dinamização do progresso tecnológico" como uma infraestrutura científico-tecnológica estreitamente inserida e vinculada ao aparato produtivo. 
-se superavitária já no ano seguinte no montante de US\$2.650,5 milhões. No período compreendido entre os anos de 2000 a 2005, as exportações brasileiras cresceram 115\%, passando de US\$55.085,6 milhões para US\$118.308,4 milhões. O superávit da balança comercial no período contribuiu para a melhora do saldo das transações correntes brasileiras, passando de um déficit de US\$ -24.224,5 milhões em 2000 para um superávit de US\$13.984,6 milhões em 2005 (BCB/DEPEC, 2016).

Em seu trabalho seminal, Kaldor $(1966,1970)$ mostra que a especialização da exportação em produtos de alta e média intensidade tecnológica seria capaz de fomentar um círculo virtuoso de crescimento no qual a expansão do produto gera expansão da produtividade (devido aos ganhos de escala) e esta, ao tornar o setor exportador mais competitivo, possibilita sua expansão (Mccombie; Thirlwall, 1994). Nesse contexto, a expansão das exportações nos setores com alta elasticidade-renda, setores de alta e média intensidade tecnológica, possui um efeito multiplicador por toda a economia, gerando emprego, renda adicional, que seria destinada ao consumo, retroalimentando a produção nacional de maneira que a economia entrasse em um círculo virtuoso de crescimento.

Diante do argumento kaldoriano, torna-se importante testar a hipótese de que o crescimento das exportações brasileiras, via aumento da demanda externa, foi capaz de induzir o crescimento sustentado na economia. Sendo assim, o objetivo do presente estudo consiste em verificar se o aumento das exportações brasileiras no período de 2000 a 2005 possui capacidade de gerar crescimento econômico sustentado na lógica estruturalista-kaldoriana. Para alcançar o objetivo proposto, será utilizado um modelo de insumo-produto fechado para o setor externo, em que o papel das exportações brasileiras será verificado por meio dos indicadores clássicos de insumo-produto e pelo método de extração hipotético. Como base de dados, serão utilizadas as matrizes de insumo-produto disponibilizadas pelo IBGE com tecnologia setor x setor para os anos de 2000 e 2005, compatibilizadas com base na taxonomia proposta por Lall (2000). Tal taxonomia foi empregada com o intuito de captar a importância do conteúdo tecnológico dos bens presentes na pauta de exportação, fundamentais para viabilizar o crescimento econômico sustentado na lógica estruturalista-kaldoriana.

Além dessa seção introdutória, o presente trabalho está estruturado como descrito a seguir. A segunda seção descreve o papel do conteúdo tecnológico das exportações para o crescimento econômico. A terceira seção 
aborda a metodologia implementada, bem como a descrição dos dados utilizados. Já na quarta seção, são discutidos os resultados e, por fim, as considerações finais do estudo são empreendidas na quinta seção.

\section{0 papel do conteúdo tecnológico das exportações para o crescimento econômico}

Na perspectiva kaldoriana, uma inserção externa dinamizadora mediante vantagens comparativas resultaria de um conjunto de medidas deliberadas pelo Estado para promover ações econômicas de caráter coletivo, expressos em relações estabelecidas dentro de cadeias produtivas e em redes de empresas que favoreçam a criação ou a incorporação de novos paradigmas tecnológicos aos setores industriais. Dessa forma, a abordagem kaldoriana é, necessariamente, setor-específica e destaca o papel da indústria como elemento-chave em um processo de crescimento equilibrado dada a capacidade deste setor em induzir o ritmo da atividade econômica nos demais setores (Oliveira, 2011).

Argumentos em defesa da importância da indústria para o crescimento econômico podem ser sintetizados no que a literatura convencionou chamar de "leis de Kaldor" (Kaldor, 1966; 1970). Estas leis apresentam os atributos inerentes à indústria de transformação que lhes conferem maior relevância para alavancar o crescimento dos demais setores produtivos e para disseminar ganhos de produtividade por toda a economia. De acordo com Kaldor (1966; 1970), as referidas leis podem ser definidas do seguinte modo:

i) O crescimento da indústria e o crescimento do produto agregado apresentam relação positiva, sendo que os setores industriais mais dinâmicos e difusores de inovações seriam os propulsores do crescimento;

ii) Existe uma relação positiva entre o produto industrial e o crescimento da produtividade industrial. Essa lei, conhecida na literatura como lei de Kaldor-Verdoorn², postula que o aumento da produção, induzido pelo aumento da demanda, leva às economias de escala e, por conseguinte, à elevação da produtividade industrial nos quais esses ganhos de produtividade devem se refletir em aumento na competitividade da economia;

iii) Elevações na taxa de crescimento das exportações geram maior crescimento do produto;

2 Para uma formalização sobre a lei de Verdoorn, ver Araújo (2013). 
iv) No longo prazo, o crescimento da economia não seria restrito pela oferta, mas pela demanda. Nesse contexto, a principal restrição de demanda ao crescimento do produto de uma economia aberta seria o balanço de pagamentos.

A terceira e a quarta leis de Kaldor (1970) estão inter-relacionadas e foram formalizadas por Dixon e Thirlwall (1975) e Thirlwall (1979). A terceira lei indica que a demanda tem um papel central na explicação dos diferenciais de taxas de crescimento entre as economias, com ênfase na evolução das exportações como o principal componente da demanda final. Já a quarta lei postula que o crescimento pode ser inibido por restrições externas e, portanto, a sustentabilidade do crescimento depende da capacidade do país em manter a competitividade de suas exportações. Os estudos de Dixon e Thirlwall (1975) e Thirlwall (1979) concluem que a taxa de crescimento da economia é determinada pela razão entre a taxa de crescimento das exportações e a elasticidade-renda da demanda por importações. Essa conclusão é denominada Lei de Thirlwall (Thirlwall, 1983). Nesse contexto, McCombie e Thirlwall (1994) destacam o desempenho do comércio exterior, particularmente das exportações, como crucial para o crescimento econômico sustentado, livre de constrangimentos externos.

Portanto, as exportações desempenhariam papel especial nos argumentos de Kaldor que permite descrever o crescimento como um processo de causação circular cumulativo (Oliveira, 2011). ${ }^{3} \mathrm{Na}$ visão de Kaldor e Thirlwall, o efeito das exportações sobre o crescimento do produto depende da estrutura produtiva de cada país. Se a economia não atingiu um nível de industrialização capaz de auferir os benefícios da causalidade cumulativa, os gestores de política econômica deveriam incentivar mudanças estruturais para alcançar tal padrão (Lamonica; Feijó, 2011). Pressupõe-se, ainda, que os estímulos da demanda seriam fortes o suficiente para, além de permitir os ganhos de escala pelo uso do estoque de capital existente, promover também a ampliação desse estoque com aquisição de máquinas e equipamentos mais modernos que, por definição, endogeinizam o progresso técnico (Feijó et al., 2013). Este progresso técnico ocorreria no sentido de aumentar a participação de setores mais intensivos em tecnologia, permitindo ganhos de competitividade não preço, o que contribuiria para a diversificação na pauta de exportação da economia.

3 Uma descrição formal do princípio da causalidade cumulativa explicando trajetória de crescimento encontra-se em Dixon e Thirlwall (1975). 
Assim, é possível afirmar que os setores de alta e média intensidade tecnológica atuariam como indutores do crescimento por serem os setores mais dinâmicos e difusores de inovações. Conforme observado por Oliveira et al. (2006) e Jayme Jr e Resende (2009), a construção teórica kaldoriana argumenta implicitamente a importância dos processos de inovação e difusão tecnológica para o crescimento econômico. O progresso técnico e sua difusão em uma economia se verificam no contexto do desenvolvimento de um sistema nacional de inovação (SNI). O conceito de SNI corresponde a uma construção institucional que impulsiona o progresso tecnológico em economias capitalistas complexas, seja produto de uma ação planejada e consciente, seja de um somatório de decisões não planejadas e desarticuladas (Freeman, 1988; Nelson, 1993; Albuquerque, 1996). ${ }^{4}$

Evidencia-se, portanto, que o desenvolvimento de um SNI possibilita maior sofisticação tecnológica à estrutura produtiva, o que se reflete em mudanças nas elasticidades-renda do comércio (maior elasticidade-renda da demanda por exportações e menor elasticidade-renda da demanda por importações) e, por conseguinte, na ruptura da restrição externa ao crescimento econômico sustentado (Missio; Jayme Jr., 2013). Nesse sentido, a ruptura da restrição externa no longo prazo, via aumento das exportações, seria alcançada por meio de um SNI desenvolvido que possui uma maior diversificação da base produtiva nacional (implicando em melhorias na competitividade não-preço) com impacto direto sobre as relações comerciais, uma vez que favorece a exportação de bens mais sofisticados tecnologicamente - de alta elasticidade-renda - e a importação de bens mais básicos - de baixa elasticidade-renda.

Os setores que atuam em segmentos de fronteira tecnológica, ou próximos a ela, viabilizariam o aumento do valor das suas exportações em decorrência de pelo menos três motivos, a saber: i) sua estrutura monopolizada ou oligopolizada; ii) alcançam os mercados externos dinâmicos (demanda externa crescente); e, iii) apresentam reduzida vulnerabilidade

4 Segundo Albuquerque (1996, p. 228), "através da construção de um sistema nacional de inovações, viabiliza-se a realização de fluxos de informação e conhecimento científico e tecnológico necessários ao processo de inovação. Esses arranjos institucionais envolvem firmas, redes de interação entre empresas, agências governamentais, universidades, institutos de pesquisa e laboratório de empresas, bem como a atividade de cientistas e engenheiros: arranjos institucionais que se articulam com o sistema educacional, com o setor industrial e empresarial e com as instituições financeiras, compondo o circuito dos agentes que são responsáveis pela geração, implementação e difusão das inovações tecnológicas". 
em relação ao grau de proteção comercial adotado pelos países. Dessa forma, quanto mais desenvolvido for o SNI, mais ampliada seria a estrutura produtiva e, assim, maiores seriam as "oportunidades tecnológicas" presentes nessa economia e mais diversificada a pauta de exportações, favorecendo o aumento do valor da mesma por meio: (i) da conquista de novos mercados; (ii) da estabilidade do crescimento do valor exportado; e (iii) do aumento da própria elasticidade-renda da demanda por exportações (Resende; Torres, 2008; Jayme Jr; Resende, 2009).

No longo prazo, o efeito sobre a economia seria a ruptura da restrição externa (balanço de pagamentos) ao crescimento, configurando um círculo virtuoso, visto que ocorre a imbricação entre o progresso técnico, o padrão de comércio e o crescimento econômico, conforme argumento kaldoriano. Nesse sentido, se do ponto de vista macroeconômico são os superávits comerciais que contam para o crescimento sustentado no longo prazo, do ponto de vista microeconômico é a intensidade tecnológica dos produtos comercializados que sustenta o resultado comercial positivo no longo prazo (Jayme Jr; Resende, 2009).

Diante da importância de um SNI maduro para o conteúdo tecnológico das exportações, Patel e Pavitt (1994) argumentam que deveria ser adotada uma estratégia de longo prazo (dinâmica) para a formação do SNI, em que os investimentos tecnológicos receberiam um tratamento privilegiado na economia nacional levando em consideração os seus efeitos benéficos, tais como os processos de aprendizado tecnológico, organizacional e mercadológico.

Por outro lado, a formação de um SNI incipiente pode ser devida à adoção de uma estratégia curto-prazista (míope), na qual os investimentos tecnológicos seriam equiparados a quaisquer outros tipos de investimento (Patel; Pavitt, 1994). Nesse caso, um SNI incompleto poderia gerar uma balança comercial deficitária, haja vista que seria pautada por importações de maior conteúdo tecnológico (elasticidade-renda alta) e exportações de baixo teor tecnológico, essencialmente commodities (baixa elasticidade-renda) o que, no longo prazo, resultaria em restrição do balanço de pagamentos ao crescimento. Além disso, o país estaria mais exposto ao problema da deterioração dos termos de troca, tornando-se vulnerável a mudanças no cenário externo, perpetuando, por conseguinte, o subdesenvolvimento de sua economia (Prebisch, 1950; Singer, 1950). Nessa mesma perspectiva, Kaldor (1966) argumenta que tais círculos viciosos de crescimento surgi- 
riam devido à incapacidade de se obter rendimentos de escala dinâmicos e devido ao efeito multiplicador do comércio, fatores que inibem a ampliação da demanda por exportações e da produção no longo prazo.

\section{Aspectos metodológicos e base de dados}

\subsection{Modelo básico de insumo-produto}

A estrutura analítica de insumo-produto, desenvolvida por Leontief (1941), fornece a descrição completa das interdependências ou interações (sobre as óticas de compra e venda) dos setores produtivos em determinado tempo e localidade (nação, região, estado) (Miller; Blair, 2009). Segundo Leontief (1986, p. 5) "a análise de insumo-produto é uma extensão prática da teoria clássica de interdependência geral que vê a economia inteira de uma região, de um país ou do mundo como um único sistema e se propõe interpretar todas as suas funções em termos das propriedades específicas mensuráveis de sua estrutura". A análise de insumo-produto, portanto, possui aderência para estudar as interdependências ou interações entre setores da economia de uma região ou país. O grau de interdependência pode ser avaliado por meio de medidas conhecidas como coeficientes de requerimento intersetorial. Esses coeficientes permitem avaliar, por exemplo, o papel dos setores produtivos em gerar crescimento econômico e como os impactos ocorridos no valor bruto da produção de uma região, oriundos de variações na demanda final desta região, podem afetar o restante da economia analisada.

O modelo de insumo-produto parte da hipótese de equilíbrio na qual a quantidade demandada é idêntica à quantidade produzida de bens e serviços e possui como premissas: (i) coeficiente tecnológico constante; (ii) retornos constantes de escala; (iii) demanda final definida exogenamente; e (iv) preços rígidos. O modelo de insumo-produto de Leontief é uma adaptação da teoria neoclássica de equilíbrio geral para o estudo empírico das inter-relações entre os vários setores de uma economia. Os fluxos inter-setoriais de bens e serviços de uma economia com $n$ setores, determinados por fatores tecnológicos e econômicos, podem ser representados por meio do modelo de insumo-produto como segue (Leontief, 1965): 


$$
\begin{gathered}
z_{11}+z_{12}+\ldots+z_{16}+y_{1}=X_{1} \\
\vdots \\
z_{61}+z_{62}+\ldots+z_{66}+y_{6}=X_{6}
\end{gathered}
$$

em que: o vetor $z$ representa as vendas intra e intersetoriais (linhas da matriz de insumo-produto) para os seis setores da economia brasileira. Os seis setores analisados estão agregados da seguinte forma: setores de alta intensidade tecnológica; setores de média intensidade tecnológica; setores de baixa intensidade tecnológica; setores intensivos em trabalho e recursos naturais; commodities; setores baseados em serviços. $O$ vetor $y$ representa a demanda final dos setores. A demanda final é composta pela formação bruta de capital fixo - I, exportações - E, consumo do governo - G e consumo das famílias - C.E, finalmente, $X$ denota o valor bruto da produção dos setores da economia. Reescrevendo a equação (1) em notação matricial, tem-se:

$$
Z+Y=X
$$

onde: Z é uma matriz $6 \times 6$, que representa os coeficientes de relações intra e intersetoriais (consumo intermediário), $Y$ é um vetor $6 \times 1$, em que é denotada a demanda final da economia, por fim, $X$ é um vetor $6 \times 1$, no qual os elementos representam o valor bruto da produção dos setores.

A equação (2) pode ser representada em termos de uma matriz de coeficientes técnicos $(A)$, conhecida como matriz de coeficientes diretos, uma vez que $A$ pode ser definida como:

$$
A=Z(\hat{X})^{-1}
$$

em que: $\hat{X}$ é a matriz diagonal de $X$ (valor bruto da produção) e cada elemento da matriz de coeficientes diretos $(A)$ é definido da seguinte forma:

$$
a_{i j}=z_{i j} / x_{j}
$$

onde: $a_{i j}$ é chamado de razão de insumo-produto, coeficiente técnico ou coeficiente de requerimento direto. Cada elemento $a_{i j}$ fornece informações sobre os efeitos diretos de uma variação exógena na demanda final. Por meio da equação (4), é possível verificar que a razão de coeficientes técni- 
cos representa a relação fixa entre os insumos utilizados na produção e o total produzido por cada setor.

A matriz $A$ em um modelo de insumo-produto pode ser ilustrada como segue:

$$
A=\left[\begin{array}{ccc}
a_{11} & \cdots & a_{16} \\
\vdots & \ddots & \vdots \\
a_{61} & \cdots & a_{66}
\end{array}\right]
$$

Na diagonal principal da matriz $A$, são explicitados os coeficientes técnicos intrassetoriais, enquanto que a diagonal secundária denota os coeficientes diretos intersetoriais. Substituindo a equação (3) na equação (2), tem-se:

$$
A X+Y=X
$$

Colocando a equação anterior em função de $Y$ (demanda final), chega-se a:

$$
X=(I-A)^{-1} Y
$$

em que: $I$ é uma matriz identidade $(6 \times 6),(I-A)^{-1}=B$ é uma matriz $(6 \times 6)$ conhecida como matriz inversa de Leontief ou matriz de coeficientes diretos e indiretos.

No modelo, com o vetor de demanda final setorial conhecido e fixo, pode-se determinar o vetor de produção total setorial por meio da equação matricial chave do modelo de insumo-produto como segue:

$$
X=B Y
$$

Este modelo básico de Leontief é classificado como de tecnologia baseada na indústria e com enfoque setor $\mathrm{x}$ setor.

\subsection{Modelo fechado de insumo-produto}

Visando alcançar o objetivo proposto, este trabalho utiliza um modelo de insumo-produto fechado para o setor externo (exportações e importações). Para implementar o fechamento do modelo, deve-se criar novas colunas e 
linhas no consumo intermediário, o que gera uma matriz $Z$ de dimensão $7 \times 7$. A nova coluna é composta pelo vetor de exportações (E), extraída do vetor de demanda final $(Y)$, enquanto a linha adicional contempla o vetor de importações setoriais $(M)$, extraída da matriz de insumos primários. Dessa forma, as exportações e as importações tornam-se endógenas ao modelo, uma vez que passam a ser componentes do consumo intermediário. Formalizando o modelo fechado de insumo-produto:

$$
\begin{gathered}
z_{11}+z_{12}+\ldots+z_{16}+z_{16+1}+y_{1}^{f}=x_{1}^{f} \\
\vdots \\
z_{61}+z_{62}+\ldots+z_{66}+z_{66+1}+y_{6}^{f}=x_{6}^{f} \\
z_{6+11}+z_{6+12}+\ldots+z_{6+16}+z_{6+16+1}+y_{6+1}^{f}=x_{6+1}^{f}
\end{gathered}
$$

onde: o vetor $z$ passa a representar as vendas intra e intersetoriais para os seis setores mais as exportações, e o vetor de demanda final $\left(Y^{f}\right)$ passa a denotar a demanda final deduzido o vetor das exportações $(E)$. Vale ressaltar que, após implementado o fechamento do modelo (equação 9), os cálculos para a obtenção da equação chave do modelo de insumo-produto fechado para o setor externo podem ser facilmente realizados de maneira análoga ao anteriormente demonstrado (vide equações 2 a 8). Dessa forma, a equação chave do modelo passa a ser:

$$
X^{f}=B^{f} Y^{f}
$$

onde: $B^{f}$ denota a matriz de coeficientes diretos, indiretos e induzidos dos seis setores da economia mais o "setor" externo.

\subsection{Indicadores clássicos de insumo-produto (multiplicador de produção, índices de interligações e setores-chave)}

A análise dos multiplicadores setoriais é uma abordagem tradicional derivada das matrizes de insumo-produto. Os multiplicadores complementam a análise da importância de determinado setor na economia, pois permitem avaliar os impactos resultantes de choques exógenos sobre determinado sistema econômico (Rodrigues et al., 2007). Os multiplicadores mais utilizados são aqueles que simulam e estimam os efeitos de uma mudança exógena na demanda final. 
O multiplicador de produção para cada setor é a soma da sua respectiva coluna na matriz inversa de Leontief $\left(B^{f}\right)$. Ele corresponde a uma variação direta, indireta e induzida da produção total da economia de todos os setores e regiões decorrente da variação exógena de uma unidade monetária da demanda final de determinado setor de uma região (Miller; Blair, 2009). Assim, o multiplicador do produto para o setor $j$ é definido como o valor total da produção adicional em todos os setores da economia que é necessário para satisfazer a uma unidade monetária adicional da demanda final do produto do setor $j$. Em termos formais, o multiplicador de produção simples para o setor $j, O j$, será dado por:

$$
O_{j}=\sum_{i=1}^{7} b_{i j}^{f}
$$

Na equação acima: $j$ é um determinado setor da economia e $b_{i j}^{f}$ representa os elementos da matriz inversa de Leontief para o modelo fechado para o setor externo.

A ideia de dependência setorial, linkages setoriais e interdependência regional são tratadas pela literatura de insumo-produto de várias formas. Rasmussen (1956) e Hirschman (1958) utilizam os índices de ligação para trás e para frente para estabelecer os setores que teriam o maior poder de encadeamento dentro da economia. Os linkages para trás (poder de dispersão) - $U_{j}$ - determinam o quanto um setor demanda dos demais setores da economia e os linkages para frente (sensibilidade da dispersão) - $U_{i}$ - determinam o quanto este setor é demandado pelos demais setores da economia.

Para o cálculo dos efeitos de encadeamento para trás e para frente, deve-se utilizar a matriz inversa de Leontief fechada para o setor externo $B^{f}=\left(I-A^{f}\right)^{-1}$ - de modo que os índices são computados da seguinte forma: Índice de ligação para trás:

$$
U_{j}=\frac{b \cdot j / 7}{B^{*}}
$$

entenda-se:

$b_{i j}$ - cada elemento da matriz $B^{f}$, sendo que $i$ são as linhas e $j$ são as colunas;

$b_{\text {. }}$ - soma das colunas de $B$;

b.. - corresponde à soma total da matriz $B f$; 


$$
\begin{aligned}
& b \cdot i / 7 \text { - é o valor médio dos elementos na linha } i ; \\
& B^{*} \text { - valor médio de todos os elementos de } B^{f} \text {, ou seja, } \\
& B^{*}=\frac{b .}{n^{2}}
\end{aligned}
$$

O índice de ligação para frente é formalizado como segue:

$$
U_{i}=\frac{b_{i} \cdot / 7}{B^{*}}
$$

em que:

$b_{i}$. - soma das linhas de $B f$

$b_{i} . / 7$ - corresponde ao valor médio dos elementos na coluna $j$;

O índice de ligação para trás $\left(U_{j}\right)$ determina o quanto um setor compra dos demais setores da economia. Se este índice for superior à unidade, isso significa que quando há uma variação na demanda final do setor $j$ o mesmo gera uma compra de insumos acima da média na economia, revelando fortes encadeamentos para trás no sistema produtivo.

Já o índice de ligação para frente $\left(U_{i}\right)$ descreve o quanto o setor $i$ vende para o restante da economia. Se $U_{i}>1$, significa dizer que a produção do setor $i$ aumenta acima da média na economia decorrente de uma variação na demanda final. Tal fato aponta que os demais setores da economia possuem uma dependência acima da média da produção do setor $i$, uma vez que o setor $i$ se destaca como forte fornecedor de insumos (encadeamentos para frente) para a economia da região.

Se um determinado setor apresentar valores de $U_{j}$ e $U_{i}$ superiores à unidade, isso significa que o mesmo é considerado setor-chave na economia de uma determinada região, visto que provoca um efeito de encadeamento de compra e venda acima da média.

\subsection{Método de extração hipotética}

O método de extração hipotética proposto por Dietzenbacher et al. (1993) aplicado à matriz de insumo-produto busca identificar setores estrategica- 
mente importantes para o desenvolvimento econômico complementando a análise de linkages para frente, para trás e setores-chave proposta por Hirschman (1958). Visto que um choque em um setor, considerado estratégico na economia, possui o poder de influenciar a produção de outros setores produtivos, a detecção destes setores é importante em termos de formulação de política econômica.

A ideia do método de extração consiste, portanto, na extração hipotética e/ou imaginária de um determinado setor da estrutura de insumo-produto. O objetivo deste método é quantificar quanto da produção total de uma economia de $n$ setores reduziria se um setor específico, dito j-ésimo setor, fosse removido da economia. No presente trabalho, isso foi modelado em um contexto de insumo-produto fechado atribuindo zero à linha e à coluna $j$ da matriz $A^{f}$, sendo $j$ o setor externo. ${ }^{5}$ Utilizando $\bar{A}_{(j)}^{f}$ para denotar a matriz sem o setor $j$ de dimensão $(n-1) x(n-1)$ e considerando que $\bar{Y}_{(j)}^{f}$ corresponde ao vetor de demanda final deduzido o setor externo, a equação chave do modelo de insumo-produto passa a ser:

$$
\bar{X}_{(j)}^{f}=\left(I-\bar{A}_{(j)}^{f}\right)^{-1} \bar{Y}_{(j)}^{f}
$$

Uma medida agregada da perda da economia (redução do VBP) caso o setor $j$ seja extraído pode ser definida como a diferença entre o VBP considerando o setor externo (equação 10) e o VBP após a extração do referido setor (equação 15). Em termos formais:

$$
T_{j}=i^{\prime} X^{f}-i^{\prime} \bar{X}_{(j)}^{f}
$$

Na equação acima $i^{\prime}$ trata-se de um vetor coluna transposto de dimensão $1 \times 7$.

$T_{j}$ pode ser interpretado como uma medida dos linkages totais do setor externo ( $j$ ), afinal a equação (16) calcula o efeito total da extração do setor externo demonstrando a importância do mesmo para a economia como um todo. Vale apontar que quanto maior o valor de $T_{j}$, maior a interdependência do setor externo com os setores produtivos da economia analisada, logo, maior a importância do setor externo para o dinamismo do crescimento da referida economia.

A equação (16) pode ser dividida pelo VBP original $\left(i^{\prime} X^{f}\right)$ e multiplicada

5 Uma forma alternativa de extrair hipoteticamente um setor é eliminar a linha e a coluna do j-ésimo setor na matriz de coeficientes técnicos - A (Miller; Blair, 2009, p. 563). 
por 100 , de modo a fornecer uma medida agregada da perda da economia em termos percentuais:

$$
\bar{T}_{j}=\left[\frac{\left(i^{\prime} X^{f}-i^{\prime} \bar{X}_{(j)}^{f}\right)}{i^{\prime} X^{f}}\right] 100
$$

Uma forma alternativa de calcular a importância do setor externo para os demais setores da economia como um todo pode ser computada da seguinte forma:

$$
T_{j}^{(A)}=\left[\left(i^{\prime} X^{f}-x_{j}\right)-i^{\prime} \bar{X}_{(j)}^{f}\right]
$$

Em que $x_{j}$ refere-se ao VBP do setor externo.

Analogamente à equação (17), pode-se calcular a perda agregada percentual da seguinte maneira:

$$
\bar{T}_{j}^{(A)}=\left[\frac{\left(i^{\prime} X^{f}-x_{j}\right)-i^{\prime} \bar{X}_{(j)}^{f}}{i^{\prime} X^{f}}\right] 100
$$

A abordagem de extração hipotética também é capaz de mensurar separadamente os linkages para frente e para trás do setor extraído. O cômputo desses linkages é importante para verificar a dependência em termos de compra e venda dos demais setores da economia no contexto hipotético de inexistência do setor externo. Pelo fato de o presente trabalho pretender analisar a hipótese kaldoriana, será computado somente os linkages para trás, afinal, estes conseguem verificar a dependência dos setores da economia em relação à exportação. Em outros termos, os linkages para trás são capazes de verificar se a produção da economia brasileira voltada para o setor externo está concentrada nos setores de maior intensidade tecnológica.

Visando calcular o poder de dispersão ou arrasto das exportações para a economia brasileira (dependência pela ótica das compras), deve-se assumir que o setor externo não compra insumos de quaisquer setores produtivos, isto é, que não existem linkages para trás do setor externo. Assim, a nova matriz de coeficientes técnicos passa a ser denotada por $\bar{A}_{(i)}^{f}$, na qual somente a coluna do setor externo na matriz de coeficientes técnicos $\left(\bar{A}_{(j)}^{f}\right)$ é 
igual a zero. Diante disso, a equação-chave do modelo de insumo-produto toma a seguinte forma:

$$
\bar{X}_{(c)}^{f}=\left(I-\bar{A}_{(q)}^{f}\right)^{-1} \bar{Y}^{f}
$$

A medida agregada da importância das exportações para a economia como um todo, ou seja, a dependência para trás do setor externo pode ser calculada por meio da diferença do VBP original e o VBP desconsiderando os linkages para trás do setor externo. Formalmente:

$$
B L_{j}=i^{\prime} X^{f}-i^{\prime} \bar{X}_{(c)}^{f}
$$

Além do cálculo de uma medida agregada da importância das exportações para o dinamismo da economia, é interessante, para o propósito do presente trabalho, mensurar a dependência para trás do setor externo sobre cada um dos demais setores da economia. Essa medida pode ser mensurada como segue:

$$
B L_{j}^{i}=X^{f}-\bar{X}_{(q)}^{f}
$$

Por intermédio da equação (22), é possível verificar quais setores são mais dependentes das exportações para a dinâmica do seu crescimento. Sendo assim, a equação (22) permite testar as hipóteses kaldorianas, pois é capaz de verificar a importância das exportações como o principal componente da demanda final. E, ainda, por meio dessa equação, é possível identificar se os setores de alta e média intensidade tecnológica atuariam como indutores do crescimento sustentado, caso seja averiguado que tais setores seriam os mais impactados pela extração hipotética das exportações.

Uma medida por unidade de produto pode ser computada por meio de uma normalização da seguinte forma:

$$
\overline{B L}_{j}^{i}=\frac{\left(x_{i}^{f}-\bar{x}_{(j) i}^{f}\right)}{x_{j}}
$$

Em síntese, se os setores mais afetados pela extração do setor externo forem os setores de alta e média intensidade tecnológica, esta economia terá um círculo virtuoso e sustentado de crescimento econômico de acordo 
com a lógica estruturalista-kaldoriana. Do contrário, se os impactos mais expressivos forem concentrados nos setores de baixa intensidade tecnológica, intensivos em trabalho e recursos naturais e commodities, a economia analisada estaria predestinada a manter o seu subdesenvolvimento, pois não causaria a ruptura da restrição externa ao crescimento econômico de longo prazo.

\subsection{Base de dados}

Este trabalho utilizará como base de dados as matrizes de insumo-produto (MIPs) disponibilizadas pelo IBGE para o Brasil. As matrizes estão dispostas com uma agregação de 55 setores produtivos com tecnologia setor $\mathrm{x}$ setor para os anos de 2000 e 2005. ${ }^{6}$ Visando verificar a importância do conteúdo tecnológico dos setores produtivos da economia brasileira no que tange às exportações, foi feita uma compatibilização das MIPs com base na taxonomia proposta por Lall (2000). ${ }^{7}$ Vale ressaltar que essa taxonomia proposta por Lall foi realizada para os setores industriais enquanto o presente trabalho classifica todos os setores produtivos constantes na matriz insumo-produto seguindo a mesma lógica de desse autor em relação ao conteúdo tecnológico dos setores.

Dessa forma, as matrizes disponibilizadas pelo IBGE foram agregadas em sete setores produtivos, a saber: i) setores de alta intensidade tecnológica consideram setores que geralmente demandam mão-de-obra mais qualificada e exigem maior intensidade de tecnologia, escala e capital, tais como produtos eletrônicos, farmacêuticos, de informática; ii) setores de média intensidade tecnológica abrangem os eletrodomésticos, automóveis entre outros; iii) setores de baixa intensidade tecnológica compreendem itens de ferro e aço, produtos de metal e suas obras.; iv) setores intensivos em trabalho e recursos naturais tais como têxteis, vestuário e calçados; v) commodities que compreende às commodities primárias e pecuária e pesca; vi) setores baseados em serviços agregam os demais produtos que não se

6 O IBGE divulga as matrizes de insumo-produto com periodicidade quinquenal, sendo que a última divulgação da MIP ocorreu no ano de 2007, referente ao ano de 2005.

7 Mais detalhes sobre a agregação dos setores das MIPs disponibilizadas pelo IBGE com a taxonomia de Lall (2000), bem como as matrizes compatibilizadas, estão disponíveis mediante solicitação aos autores. 
enquadram em nenhuma das cinco categorias acima como, por exemplo, eletricidade, comércio e os serviços de forma geral; e vii) setor externo. É importante salientar que todos os procedimentos adotados ao longo da formulação e compatibilização da base de dados do trabalho foram os mesmos para os anos 2000 e 2005.

A escolha do período analisado deve-se ao fato de que, conforme supracitado, as exportações brasileiras terem aumentado consideravelmente nesse período de tal modo a reverter o déficit do saldo comercial. Essa melhora da balança comercial impactou positivamente o saldo em transações correntes, o qual saiu de uma situação deficitária atingindo, em 2005, o maior superávit registrado nos anos recentes (US\$13.984,6 milhões). Conforme afirma Jayme Jr e Resende (2009), os saldos em transações correntes refletem com mais precisão a influência dos fatores estruturais, estáveis no curto prazo, do que os saldos comerciais. Diante do exposto, o período de 2000 e 2005 é capaz de atender ao objetivo do presente estudo que pretende analisar a importância do crescimento das exportações sob a ótica estruturalista-kaldoriana.

\section{Discussão dos resultados}

Do ponto de vista estruturalista-kaldoriano, o aumento das exportações em bens de alta e média intensidade tecnológica, alta elasticidade-renda, é capaz de fomentar um círculo virtuoso de crescimento. De forma complementar, a literatura neo-schumpeteriana considera que o desenvolvimento tecnológico é o elemento propulsor do crescimento sustentado. Assim, conforme Jayme Jr e Resende (2009), enquanto os superávits comerciais são importantes para o crescimento de longo prazo pela ótica macroeconômica, a intensidade tecnológica dos produtos comercializados, derivada da ótica microeconômica, sustentaria o resultado comercial positivo com o passar do tempo.

Diante disso, a análise do modelo de insumo-produto fechado para o setor externo permite verificar se a mudança estrutural ocorrida na balança comercial brasileira entre os anos 2000 e 2005 possui a capacidade de propiciar o crescimento econômico sustentado na economia interna, uma vez que seus indicadores são capazes de averiguar a interdependência do setor externo com os demais setores da economia, além de verificar se 
o conteúdo tecnológico presente nos setores exportadores segue a lógica estruturalista-kaldoriana.

Nesse contexto, uma maneira de avaliar a importância das exportações para a economia brasileira dar-se-á por intermédio da interdependência do setor externo com os demais setores da economia. Essas interligações, a montante e a jusante, das atividades produtivas podem ser avaliadas por meio dos índices desenvolvidos por Rasmussen (1956) e Hirschman (1958). Os resultados desses índices de interligação, para cada setor da MIP do Brasil, compatibilizada com base na tipologia de Lall (2000), estão reportados nas Tabelas 1 e 2 (colunas 2 a 4) para os anos de 2000 e 2005, respectivamente.

Por meio da análise da coluna 2 das Tabela 1 e 2, nota-se que os setores com poder de dispersão acima da média foram os de média e alta intensidade tecnológica e o setor externo para ambos os anos. Ou seja, os referidos setores mostraram-se capazes de induzir a atividade produtiva nacional. Quanto aos setores com fortes encadeamentos para frente (coluna 3 das Tabelas 1 e 2), isto é, setores demandados pelos demais setores da economia no ano de 2000, podem ser citados os de média intensidade tecnológica, intensivos em trabalho e recursos naturais, baseados em serviços e o setor externo. Para o ano de 2005, somente o setor externo deixa de ter sensibilidade de dispersão acima da média comparativamente ao ano de 2000. Diante do exposto, os setores de média intensidade tecnológica e o externo apresentaram-se como setores-chave da economia no ano 2000, enquanto em 2005 somente o setor de média intensidade tecnológica permanece com encadeamentos para frente e para trás acima da média. As intra e inter relações desses setores com os demais setores induzem a um aumento na produção na cadeia produtiva como um todo.

Conforme apontado por Palermo et al. (2010), embora os índices de interligações de Rasmussen-Hirschman permitam diagnosticar os setores com maior interdependência na estrutura produtiva da economia, os multiplicadores de produção complementam a análise da importância de determinado setor na economia, pois permitem avaliar os impactos diretos, indiretos e induzidos sobre a cadeia produtiva nacional advindos da variação da demanda final. Analisando os multiplicadores de produção (colunas 5 e 6 das Tabelas 1 e 2), percebe-se que os setores que geraram impacto acima da média no produto da economia foram os de alta e média intensidade tecnológica e externo nos anos de 2000 e 2005. 
Tabela 1 Índices de interligação, setor-chave, multiplicador de produção e impacto sobre o VBP advindo da extração hipotética das exportações do Brasil, 2000.

\begin{tabular}{|c|c|c|c|c|c|c|c|}
\hline \multirow[b]{2}{*}{ Setor } & \multicolumn{2}{|c|}{ Linkages } & \multirow[b]{2}{*}{ 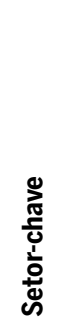 } & \multirow{2}{*}{ 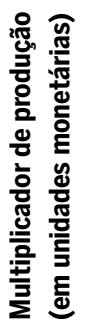 } & \multirow[b]{2}{*}{ 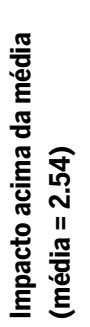 } & \multirow{2}{*}{ 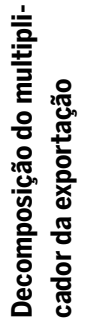 } & \multirow[b]{2}{*}{ 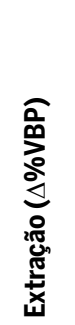 } \\
\hline & 急 & $\begin{array}{l}\stackrel{0}{ \pm} \\
\text { 논 }\end{array}$ & & & & & \\
\hline Alta intensidade tecnológica & Trás & - & - & 3.07 & Acima & 0.11 & $-19 \%$ \\
\hline Média intensidade tecnológica & Trás & Frente & Chave & 2.88 & Acima & 0.63 & $-16 \%$ \\
\hline Baixa intensidade tecnológica & - & - & - & 2.24 & - & 0.14 & $-6 \%$ \\
\hline $\begin{array}{l}\text { Intens. em trabalho e recursos } \\
\text { naturais }\end{array}$ & - & Frente & - & 2.51 & - & 0.36 & $-13 \%$ \\
\hline Commodities & - & - & - & 2.23 & - & 0.13 & $-22 \%$ \\
\hline Baseados em serviços & - & Frente & - & 1.83 & - & 0.49 & $-6 \%$ \\
\hline Externo & Trás & Frente & Chave & 3.03 & Acima & 1.17 & $-100 \%$ \\
\hline
\end{tabular}

Fonte: Elaboração dos autores.

Tabela 2 Índices de interligação, setor-chave, multiplicador de produção e impacto sobre o VBP advindo da extração hipotética das exportações do Brasil, 2005.

\begin{tabular}{|c|c|c|c|c|c|c|c|}
\hline \multirow[b]{2}{*}{ Setor } & \multicolumn{2}{|c|}{ Linkages } & \multirow[b]{2}{*}{ 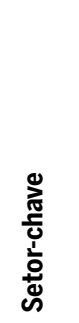 } & \multirow{2}{*}{ 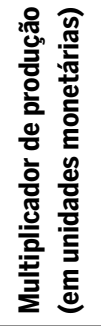 } & \multirow{2}{*}{ 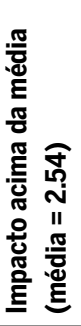 } & \multirow{2}{*}{ 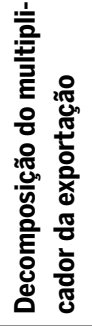 } & \multirow[b]{2}{*}{ 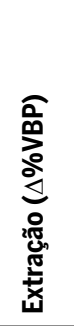 } \\
\hline & 晃 & 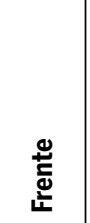 & & & & & \\
\hline Alta intensidade tecnológica & Trás & - & - & 4.00 & Acima & 0.09 & $-14 \%$ \\
\hline Média intensidade tecnológica & Trás & Frente & Chave & 3.59 & Acima & 1.37 & $-31 \%$ \\
\hline Baixa intensidade tecnológica & - & - & - & 2.42 & - & 0.20 & $-11 \%$ \\
\hline $\begin{array}{l}\text { Intens. em trabalho e recursos } \\
\text { naturais }\end{array}$ & - & Frente & - & 2.78 & - & 0.68 & $-26 \%$ \\
\hline Commodities & - & - & - & 3.06 & - & 0.36 & $-40 \%$ \\
\hline Baseados em serviços & - & Frente & - & 1.85 & - & 0.90 & $-8 \%$ \\
\hline Externo & Trás & - & - & 4.91 & Acima & 1.31 & $-100 \%$ \\
\hline
\end{tabular}

Fonte: Elaboração dos autores. 
Em se tratando, especificamente, do setor externo, pode-se inferir que o mesmo possui a capacidade de alavancar a produção dos demais setores da economia em ambos os anos analisados. Contudo, o setor externo perde importância no que tange aos seus encadeamentos intersetoriais no ano de 2005, tendo em vista que o mesmo perde a sensibilidade de dispersão acima da média deixando de ser um setor-chave para o ano em questão.

Analisando de forma pormenorizada o conteúdo tecnológico dos setores exportadores (coluna 7 das Tabelas 1 e 2), pode-se perceber que o setor de média intensidade tecnológica seguido pelos setores baseado em serviços e intensivos em trabalho e recursos naturais seriam os setores que mais se beneficiariam com o choque na demanda final no ano de 2000. Quanto ao ano de 2005, os setores mais beneficiados permaneceriam os mesmos do período anterior. Resultado que merece destaque é a expressiva mudança no que se refere ao efeito multiplicador dos setores commodities e de alta intensidade tecnológica. Enquanto o setor commodities aumenta seu efeito multiplicador sobre a economia de 0,13 em 2000 para 0,36 em 2005, o setor de alta intensidade tecnológica perde importância nesse quesito, pois o inexpressivo montante de 0,11 registrado em 2000 reduz ainda mais no ano de 2005 (0,09). Portanto, o setor de commodities parece ganhar importância na pauta de exportação, tendo em vista que seu multiplicador aumentou $169 \%$ entre os anos analisados em detrimento da perda de importância do setor de alta intensidade tecnológica no montante de $16 \%$.

Dando continuidade à verificação do conteúdo tecnológico das exportações, a extração hipotética das exportações permite verificar quais setores seriam os mais prejudicados caso as exportações fossem inexistentes. Em outros termos, a extração das exportações possibilita a identificação dos setores estrategicamente importantes para o crescimento econômico do país. No ano de 2000, o setor brasileiro mais prejudicado com a ausência das exportações seria o setor commodities, uma vez que a redução do seu produto seria da ordem de $22 \%$ (coluna 8 da Tabela 1). No ano de 2005, a situação assemelha-se com o período anterior, afinal, o setor commodities continuaria sendo o mais impactado negativamente, reduzindo seu produto em $40 \%$ (coluna 8 da Tabela 2). No mesmo sentido, o setor de média intensidade tecnológica também passaria a ser mais dependente das exportações entre os anos de 2000 e 2005. Sendo assim, a perda de produto por ocasião da ausência das exportações para o referido setor que em 2000 
seria no montante de $16 \%$ (coluna 8 da Tabela 1 ) passaria para $31 \%$ em 2005 (coluna 8 da Tabela 2).

Resultados preocupantes decorrem da análise da mudança estrutural no conteúdo tecnológico dos setores exportadores brasileiros de alta intensidade tecnológica e intensivos em trabalho e recursos naturais. Conforme pode ser percebido pela análise da coluna 8 da Tabela 1, no ano de 2000, o setor de alta intensidade tecnológica seria o segundo setor com maior redução em seu produto em decorrência da extração das exportações, enquanto em 2005 o mesmo passa para o quarto setor com maior perda em seu produto (coluna 8 da Tabela 2). Ou seja, enquanto em 2000 o referido setor perderia $19 \%$ do seu produto, em 2005 essa perda de produto por ocasião da inexistência das exportações seria de 14\%, evidenciando a incapacidade das exportações brasileiras em alavancar o crescimento do produto deste setor. Adicionalmente, o setor intensivo em trabalho e recursos naturais torna-se mais dependente das exportações no período analisado, haja vista que o citado setor perde $13 \%$ de seu produto em 2000 enquanto em 2005 a redução do produto, em virtude da ausência de exportações, seria o dobro do período anterior.

Diante do exposto acerca das exportações brasileiras, três possíveis desvantagens decorrentes do tipo de especialização comercial podem ser destacadas: (i) os mercados internacionais de commodities e produtos intensivos em trabalho e recursos naturais são menos dinâmicos do que os de produtos mais sofisticados tecnologicamente; (ii) devido ao fato de os produtores de commodities e produtos intensivos em trabalho e recursos naturais serem, majoritariamente, price takers, os preços desses bens estão mais suscetíveis às variações em relação aos preços de produtos mais intensivos em tecnologia, aumentando o grau de incerteza a respeito da evolução das receitas desses produtores com implicações negativas sobre o investimento e, (iii) commodities e produtos intensivos em trabalho e recursos naturais estão mais sujeitos a práticas anticomerciais (protecionistas), sobretudo em países desenvolvidos.

Portanto, apesar da melhora do resultado comercial do país no período analisado - de déficit para superávit - em virtude do crescimento das exportações acima do aumento das importações, a expansão das exportações brasileiras não seria capaz de induzir um círculo virtuoso de crescimento econômico sustentado sob a lógica estruturalista-kaldoriana. Essa conclusão deve-se ao fato de que para Kaldor $(1966,1970)$ os setores que dina- 
mizariam a economia seriam os setores exportadores mais intensivos em tecnologia e, portanto, o aumento de participação dos referidos setores permitiria ganhos de competitividade não preço, contribuindo para a diversificação na pauta de exportação da economia. Dessa forma, o aumento das exportações desses setores seria alcançado pela conquista de novos mercados, pela estabilidade do crescimento do valor exportado e também pelo aumento da própria elasticidade-renda da demanda por exportações o que, no longo prazo, causaria a ruptura da restrição externa ao crescimento.

Entretanto, para o caso brasileiro no período de 2000 a 2005, os setores mais dependentes da exportação em relação ao aumento de seu produto foram os setores de commodities, de média intensidade tecnológica e intensivos em trabalho e recursos naturais, estando, portanto, na contramão da lógica estruturalista-kaldoriana para o crescimento virtuoso da economia. Evidências similares foram encontradas por Coutinho et al.(2003) e Jayme Jr e Resende (2009) demonstrando que o Brasil é especializado na exportação de produtos de baixa intensidade tecnológica e, portanto, o país ainda não apresenta uma inserção internacional competitiva nas categorias de alta intensidade tecnológica. Com isso, a economia brasileira estaria sujeita à atuação da deterioração dos termos de troca, o que a torna vulnerável às políticas externas, perpetuando, por conseguinte, o subdesenvolvimento econômico.

Além disso, a incapacidade de o efeito multiplicador gerar, em longo prazo, incentivos à ampliação da demanda por exportações dos setores na fronteira tecnológica, como observado para a economia brasileira nos anos de 2000 e 2005, pode ocasionar um círculo vicioso de crescimento. Essa constatação do presente trabalho indica que o SNI brasileiro ainda apresenta um baixo grau de desenvolvimento. Conforme argumentam Missio e Jayme Jr (2013), a ausência de um SNI maduro pode gerar desequilíbrios na balança comercial advindos da baixa competitividade dos seus produtos no mercado internacional, o que se traduz em uma elasticidade-renda da demanda por exportações menor que a elasticidade-renda da demanda por importações. Sendo assim, o SNI brasileiro possui papel limitado na indução da atividade econômica pelo fato de não ser capaz de promover uma maior diversificação da base produtiva nacional, afinal, a expansão das exportações concentrou-se nos setores de baixo conteúdo tecnológico, essencialmente commodities, o que não causaria a ruptura da restrição externa ao crescimento econômico do país no longo prazo. 


\section{Considerações finais}

Tendo em vista a mudança na estrutura comercial do país decorrente da nova perspectiva de modernização industrial, da retomada do crescimento econômico interno e do crescimento econômico mundial, fez-se necessário o entendimento do conteúdo tecnológico das exportações brasileiras de modo a verificar se a expansão das exportações teria capacidade de arrasto do crescimento econômico sustentado seguindo a lógica estruturalista-kaldoriana. Para alcançar o objetivo proposto, um modelo de insumo-produto fechado para as exportações foi utilizado. Nele, o papel das exportações brasileiras foi verificado por meio dos indicadores clássicos de insumo-produto e pelo método de extração hipotético. Para tanto, a base de dados utilizada foi as matrizes de insumo-produto disponibilizadas pelo IBGE com tecnologia setor $x$ setor para os anos de 2000 e 2005 compatibilizadas com base na taxonomia proposta por Lall (2000).

A análise dos resultados para a matriz de insumo-produto brasileira, por meio dos índices de ligações Rasmussen-Hirschman, revelou que os setores-chave da economia foram o setor de média intensidade tecnológica e o setor externo, em 2000; enquanto em 2005 somente o setor de média intensidade tecnológica figurou como setor-chave. Quanto ao multiplicador de produção, os setores que seriam capazes de gerar impacto acima da média no produto da economia foram os de alta e média intensidade tecnológica e externo, nos anos de 2000 e 2005. Além disso, no que se refere ao conteúdo tecnológico dos setores exportadores, foi perceptível que o setor de média intensidade tecnológica seguido pelos setores baseados em serviços e intensivos em trabalho e recursos naturais seriam os setores que mais se beneficiariam com o choque na demanda final tanto em 2000 quanto em 2005.

Quanto ao impacto causado no produto dos setores em decorrência da extração das exportações, entre 2000 e 2005, os setores mais dependentes das exportações em relação ao aumento de seu produto foram os setores de commodities, de média intensidade tecnológica e intensivos em trabalho e recursos naturais, em detrimento da redução de tal dependência nos setores de alta intensidade tecnológica. Essa conclusão indica que o aumento das exportações brasileiras deveu-se, principalmente, ao crescimento da demanda chinesa por commodities e recursos naturais ocorrida no período analisado. 
Diante disso, apesar da melhora do resultado comercial do país verificada no período, a expansão das exportações brasileiras não seria capaz de induzir um círculo virtuoso de crescimento econômico sustentado sob a lógica estruturalista-kaldoriana. Essa constatação do presente trabalho indica que o SNI brasileiro ainda apresenta um baixo grau de desenvolvimento, possuindo papel limitado na indução da atividade econômica pelo fato de não ser capaz de promover uma maior diversificação da base produtiva nacional. Tal resultado é preocupante, afinal, o comércio exterior especializado em commodities, bens de baixa intensidade tecnológica e bens intensivos em trabalho e recursos naturais expõe a economia brasileira ao problema da deterioração dos termos de troca, tendo em vista que torna o país dependente de condições favoráveis na demanda externa, o que não gera a ruptura da restrição do balanço de pagamentos no longo prazo, perpetuando, por conseguinte, o subdesenvolvimento econômico.

Como agenda de pesquisa, pretende-se analisar a existência da lógica estruturalista-kaldoriana, no que se refere ao conteúdo tecnológico das exportações, em outros países em desenvolvimento e desenvolvidos, de modo a contrastar o processo de crescimento do Brasil com essas economias.

\section{Referências}

ALBUQUERQUE, E. M. Notas sobre a contribuição de Kenneth Arrow para a fundamentação teórica dos sistemas nacionais de inovações. Revista Brasileira de Economia, v. 50, n. 2, p. 227-242, 1996.

ARAÚJO, R. A. Cumulative causation in a structural economic dynamic approach to economic growth and uneven development. Structural Change and Economic Dynamics, v. 24, p. 130-140, 2013.

BANCO CENTRAL DO BRASIL. Indicadores Econômicos. Brasília: Departamento Econômico (DEPEC/BCB). Disponível em: <https://www3.bcb.gov.br/sgspub/consultarvalores/consultarValoresSeries.do?method=consultarValores $>$ Acesso em: janeiro de 2016.

COUTINHO, L.; HIRATUKA, C.; SABBATINI, R. O desafio da construção de uma inserção externa dinamizadora. Texto produzido para o Seminário Brasil em Desenvolvimento, set. 2003. Disponível em: <www.ie.ufrj.br/desenvolvimento/papers.php>. Acesso em: 30 de janeiro de 2016.

DIETZENBACHER, E.; VAN DER LINDEN, J. A.; STEENGE, A. E. The regional extraction method: EC input-output comparisons. Economic Systems Research, v. 5, n. 2, p. 185-207, 1993.

DIXON, R.; THIRLWALL, A. P. A model of regional growth-rate differences on Kaldorian lines. Oxford Economic Papers, v. 27, n. 2, p. 201-214, 1975. 
FAJNZYLBER, R. F. La industrialización trunca de América Latina. México: Nueva Imagem, 1983.

FEIJÓ, C.; OLIVEIRA, D. R.; LAMONICA, M. C. Mudança estrutural nos anos 1990 e 2000: a contribuição das MPME para o crescimento econômico. Séries working paper BNDES/ ANPEC, Mimeo, 2013.

FERRAZ, J. C.; KUPFER, D.; HAGUENAUER, L. Made in Brazil: desafios competitivos para a indústria brasileira. Rio de Janeiro, Campus, 1995.

FREEMAN, C. Japan: a new national system of innovation? In: DOSI, G.; FREEMAN, C.; NELSON, R.; SILVERBERG, G.; SOETE, L. (Eds.). Technical change and economic theory. London: Pinter, p. 330-348, 1988.

HIRSCHMAN, A. O. The strategy of economic development. New Haven: Yale University Press, 1958.

INSTITUTO BRASILEIRO DE GEOGRAFIA E ESTATÍSTICA. Matriz de insumo-produto: Brasil 2000/2005. Disponível em: <http://www.ibge.gov.br/home/estatistica/economia/matrizinsumo_produto/>. Acesso em: maio de 2014.

JAYME JR., F. G.; RESENDE, M. F. C. Crescimento econômico e restrição externa: teoria e a experiência brasileira, In: MICHEL, R.; CARVALHO, L. (Org.) Crescimento econômico: setor externo e inflação. Rio de Janeiro: IPEA, 2009.

KALDOR, N. Causes of the Slow Rate of Economic Growth of the United Kingdom. Cambridge University Press, 1966.

KALDOR, N. The Case for Regional Policies. Scottish Journal of Political Economy, vol. 18, p. 337-348, 1970.

KUPFER, D. Tecnologia e emprego são realmente antagônicos? In: SICSÚ, J.;PAULA, L. F.; MICHEL, R. (Orgs.). Novo-Desenvolvimentismo: um projeto nacional de crescimento com equidade social. Barueri: Manole, 2005.

LALL, S. The technological structure and performance of developing country manufactured exports, 1985-98. Oxford Development Studies, v. 28, p. 337-69, 2000.

LAMONICA, M. T.; FEIJÓ, C. Crescimento e industrialização no Brasil: uma interpretação à luz das propostas de Kaldor. Revista de Economia Política, v. 31, n. 1 (121), p. 118-138, janeiro-março/2011.

LAMONICA, M. T.; OREIRO, J. L. C.; FEIJÓ, C. Acumulação de Capital, Restrição Externa, Hiato Tecnológico e Mudança Estrutural: Teoria e Experiência Brasileira. Estudos Econômicos, v. 42, n.1, p. 151-182, 2012.

LEONTIEF, W. The Structure of American Economy, 1919-1929. Cambridge: Harvard University Press, MA, 1941.

LEONTIEF, W. Input-output economics. Oxford: University Press, 1986.

MCCOMBIE, J. S. L.; THIRLWALL A. P. Economic growth and the balance of payments constraint. New York: St. Martin's Press, 1994.

MILLER, R. E.; BLAIR, P. D. Input-output analysis: foundations and extensions. New York: Cambridge University Press, 2009.

MISSIO, F. J.; JAYME JR, F. G. Restrição externa, nível da taxa real de câmbio e crescimento em um modelo com progresso técnico endógeno. Economia e Sociedade, Campinas, v. 22, n. 2 (48), p. 367-407, ago. 2013. 
NELSON, R. R. (Ed.) National innovation systems: a comparative analysis, Oxford: Oxford U. Press, 1993.

OLIVEIRA, D. R. O processo de mudança estrutural no pós-1990: uma análise da heterogeneidade produtiva na perspectiva kaldoriana. 2011. Tese (Doutorado em Economia). Faculdade de Economia, Universidade Federal Fluminense, 2011.

OLIVEIRA, F.H.; JAYME JR, F.G.; LEMOS, M.B. Increasing returns to scale and international diffusion of technology: an empirical study for Brazil. World Development, Canadá, v. 34, n. 1, p. 1-40, 2006.

PALERMO, P.U; PORSSE, A.A; PEIXOTO, F. C. Relações setoriais e interdependência regional da economia gaúcha: análise com um modelo inter-regional de insumo-produto. Ensaios FEE, v. 31, n. 1, 2010.

PATEL, P.; PAVITT, K. National Innovation Systems: why they are important, and how they might be measured and compared. Economics of innovation and New Technology, v. 3, n. 1, p. 77-95, 1994.

PREBISCH, R. The Economic Development of Latin America and its Principal Problems. Lake Sucess, ECLA, 1950.

RASMUSSEN, P. Studies in intersectorial relations. Amsterdam: North Holland, 1956.

RESENDE, M. F. C.; TORRES, D. R. National Innovation System, Trade Elasticities and Economic Growth. In: Anais do XXXVI Encontro Nacional de Economia (ANPEC), Salvador, 2008.

RODRIGUES, R. L.; PARRÉ, J. L.; MORETTO, A.C.; ALVES, A. F. Transformações na estrutura produtiva da economia paranaense nos anos 80 e 90. Revista de Economia Aplicada, v. 11, p. 73-93, 2007.

SINGER, H. The Distribution of Gains Between Investing and Borrowing Countries. American Economic Review, Papers and Proceedings, vol. 40, 1950.

THIRLWALL, A. The balance of payments constraint as an explanation of international growth rates differences. Banca Nazionale del Lavoro Quarterly Review, v. 128, 1979.

THIRLWALL, A. A plain man's guide to Kaldor's growth laws. Journal of Post Keynesian Economics, v. 5, n. 3, p. 345-358, 1983.

\section{Sobre os autores}

Joilson de Assis Cabral - cabraljoilson@gmail.com

Professor do Departamento de Ciências Econômicas da Universidade Federal Rural do Rio de Janeiro campus Seropédica e pesquisador do Núcleo de Análises Regionais, Setoriais e Políticas Públicas.

Maria Viviana de Freitas Cabral - mvivianafreitas@gmail.com

Professora do Departamento de Ciências Econômicas e do Programa de Pós-Graduação em Desenvolvimento Territorial e Políticas Públicas da Universidade Federal Rural do Rio de Janeiro campus Seropédica e pesquisadora do Núcleo de Análises Regionais, Setoriais e Políticas Públicas.

Daniel Ribeirode Oliveira-daniel.eco@uol.com.br

Professor do Departamento de Ciências Econômicas e do Programa de Pós-Graduação em Gestão e Estratégia da Universidade Federal Rural do Rio de Janeiro campus Seropédica.

Os autores, agradecem à bolsista de iniciação científica (PROIC/UFRRJ) Thandara Maria Kathleen da Silva pelo auxílio na compatibilização das MIPs. Os autores agradecem também os pareceristas anônimos por suas oportunas contribuições. 
Cabral, Cabral \& Oliveira

\section{Sobre o artigo}

Recebido em 22 de setembro de 2015. Aprovado em 29 de abril de 2016. 